\title{
A Marine's journey from battle injury to employment in home community
}

\author{
Casey Linstad* and David J. Schafer \\ Veterans Affairs Healthcare System, Minneapolis, MN, USA
}

Received 14 February 2013

Accepted 4 March 2014

\begin{abstract}
After surviving a severe brain injury from a rocket-propelled grenade (RPG) blast and working daily to reclaim his life, one of the military's finest was ready to pursue community employment. At 27-years-old, he completed an 8-year-long, comprehensive traumatic brain injury rehabilitation program by making an autobiographical documentary. The documentary served as a stepping stone for his community employment as well as a means to encourage others to keep working toward their goals. He is now successfully employed, on a part-time basis, with a local retailer, in his home community. This paper outlines the progression from initial concept to a completed documentary. It tracks his experiences and accomplishments through years of rehabilitation therapy, through making an autobiographical documentary, to bridging a transition from his identity as a rehabilitation patient to a working member of his home community.
\end{abstract}

Keywords: Documentary movie, work, speech therapy, recreation therapy

\section{Introduction}

Traumatic brain injury (TBI) is one of the signature injuries of American troops wounded in Iraq and Afghanistan [1]. These injuries are often classified as concussion/mild TBI, moderate TBI, severe TBI or penetrating/open head injury. The Defense and Veterans Brain Injury Center (DVBIC) is a part of the U.S. military health system founded in 1992 by Congress and charged with the mission to serve active duty military, their beneficiaries, and veterans with traumatic brain injuries. This is done through clinical care, clinical research initiatives, and educational programs. According to a recent (2013) DVBIC [1] report, the total number of U.S. service members, worldwide, diagnosed with TBI since 2000 , is over 287,000 . Of that number 4,356 , approximately $(1.5 \%)$, were penetrating/open head injuries. The purpose of this paper is to demonstrate how the making of an autobiographi-

\footnotetext{
*Corresponding author: Casey Linstad, CTRS, 1 Veterans Drive (135-R), Minneapolis, MN 55417, USA. Tel.: +1 612629 7618; Fax: +1612 467 5248; E-mail: casey.linstad@va.gov.
}

cal movie proved to be a successful way to support the transition of a young Marine, who suffered a penetrating/open head injury, from rehabilitation patient to a successfully employed member of his home community.

The therapeutic use of story-telling, visual arts, journaling and reminiscence/life review are interventions that are central to therapeutic recreation practice [2]. Little has been documented regarding the use of autobiographical film-making for rehabilitation after traumatic brain injury. In this case, the patient wanted to tell his story and to motivate others in their recovery from brain injury. Given the patient's previously stated lifelong goal of becoming a movie director the idea of telling his story using an autobiographical film was borne. The patient and the rehabilitation team collaborated to develop a project utilizing established selfdiscovery/self-expression interventions [2] from traditional therapeutic recreation practice. This paper will outline the nature of the patient's injuries, discuss his development and achievement of rehabilitation goals in cooperation with the rehabilitation team, describe the making of an autobiographical film, and illustrate a 
transition to part-time gainful employment in his home community.

\section{The injury}

In 2004, a distinguished member of the United States Marine Corps was critically injured in an RPG blast. At the time of his injury, he was serving with the Marine infantry, on a mission in a war zone in Iraq. He sustained a severe penetrating brain injury which resulted in loss of part of the left side of his brain and skull, and loss of the use of the right side of his body. His initial recovery required multiple brain surgeries and he endured numerous battles with infection. He was given a $5 \%$ chance to survive during the initial phase of his recovery. Against these odds, he survived and began the long road of recovery and rehabilitation.

From the beginning, relearning to talk and relearning to walk were two of his most desired and most challenging long-term goals for recovery. However, the brain injury resulted in other lost abilities. Due to the location of his brain injury, he suffered severe aphasia [3] (a multimodality reduction in capacity to decode (interpret) and encode (formulate) meaningful linguistic elements), apraxia of speech [3] (impairment in the programming of articulatory movements) and dysarthria [3] (disturbance in the muscular control of the speech mechanism). Along with the loss of communication skills, the injury resulted in cognitive impairments often associated with TBI. The most common cognitive impairments following TBI include: attention, memory, new learning, planning, problemsolving, initiation, impulsivity, self-regulation of mood and emotional reactions, and self-awareness [4]. Rehabilitation goals, in this case, addressed some of the common cognitive sequelae. The injury also resulted in left-sided visual neglect. In addition, he suffered physical impairments, primarily loss of function on the right side of his body. He has worked diligently to regain his speech, language, and cognitive abilities and his ability to walk.

From 2004 to 2012, he worked to regain what he lost and to pursue his life goals. He began his rehabilitation in an intensive inpatient rehabilitation program, where he approached the setting and achievement of goals with perseverance and tenacity. In 2005, his journey progressed to outpatient therapy which included a full complement of rehabilitation specialists (physiatry, social work, psychology, physical, occupational, speech, and recreational therapies, and eventu- ally vocational rehabilitation), two intensive aphasia programs and two short stays in a residential transitional rehabilitation program. He showed consistent effort throughout each phase of the rehabilitation process.

Approximately six years after his injury, his recovery and rehabilitation course had reached several milestones. He had moved into a remodeled home that better accommodated his needs, allowing him to realize greater living independence. He had developed improved ambulation ability and walked safely using a leg brace and a cane. He had developed a number of single-handed skills and techniques that allowed his independence with activities of daily living (ADLs). He made slow and steady improvements in his ability to communicate, both verbally and non-verbally, always holding the desire to "learn to talk" in clear view. He completed two intensive aphasia therapy programs, the first of which involved 4 hours of communication therapy per day, both individual and group, for 4 consecutive days for 3 weeks; and the second of which involved 6 hours of therapy per day, both individual and group, for 5 consecutive days for 4 weeks. He also developed his social and recreational abilities, the highlight of which was accompanying his father and brother on a successful African hunting safari, where he hunted and shot an African kudu (a large antelope with tall spiraling horns).

Looking toward the future, he was ready to move on to new challenges and started to contemplate what he wanted to do with the rest of his life. The next phase of his recovery would be focused on completion of his rehabilitation programming and re-entering his home community, a small city of approximately 35,000 people in the upper Midwest. He began a work therapy program in the Veterans Affairs Healthcare System (VAHCS), to learn and practice work-related skills in the context of residual communication, cognitive and physical challenges. He worked with the medical center housekeeping staff for a period of time where he developed additional single-handed techniques to meet the requirements of that work, with the support of a vocational rehabilitation specialist. He was later given a job in the central supply area of the hospital, receiving and filling orders of supplies for hospitalwide delivery. The rehabilitation team anticipated this position would challenge his communication, cognitive and physical skills at a level not previously approached. With his usual determination, and with support of a vocational rehabilitation job coach, he succeeded in learning the required tasks and proceeded to successfully meet the requirements of the position. 
At this point in his recovery (in 2010), the challenge for the rehabilitation team was to provide an opportunity that would help him put into practice all the skills he had learned and begin the process of transition to gainful community employment. Specifically, the rehabilitation team wanted him to mark his significant and consistent work effort with a final capstone project. He previously expressed a long term life goal of becoming a professional movie director. The making of a autobiographical movie, covering his life and experiences to date, seemed like a great first step toward that goal. This project proved to be an excellent way to capture the benefits of his focused rehabilitation efforts.

\section{The movie project}

Creating a movie is a complex, multi-layered project. It requires creative abilities, focused attention to detail, reliable short-term memory skills, good organization skills and effective problem-solving skills. It demands creativity, a vision for the larger scope of the project and a sense for the impact of the finished project for those who view it. Creating an autobiographical documentary gave him a way to express his character, values and dreams beyond words alone. As the 18-month long project developed and progressed, and the finished product became more real, additional reasons for making this movie began to emerge. This was a way for him to begin to pay-it-forward to others who need inspiration or motivation to never give up on their goals. It also allowed him to integrate his experiences and gain control over the trauma he experienced. Finally, he was able to educate his home community, about his journey to recovery, in a unique way.

The making of this movie was inspired by his life story and his ability to continually challenge himself to succeed. He set goals and applied consistent effort toward reaching each goal he attempted. He never accepted "okay" as good enough. A popular song, "Walk", by the Foo Fighters [5] proved to be an inspiring backdrop to the movie. It helped to give words to the challenges he faced. A portion of the lyrics of that song that was particularly inspirational is as follows:

I'm learning to walk again. I believe I've waited long enough.

Where do I begin? I'm learning to talk again.

Can't you see I've waited long enough?

Where do I begin?
These are the very same questions he asked himself. Each time he approached the obstacles related to his injury and met a goal; he would immediately identify the next step toward reclaiming his life.

This project challenged his ability to communicate at a level that is necessary in the workplace and in society. Aphasia and apraxia of speech were the most prominent obstacles. Sessions could not be rushed, decisions required time for understanding, pondering and execution. The overall timeline of this project would not be short, and would require a team approach. He relived the realities of the severity of his injury and the dramatic life changes that ensued, as he reviewed, explored and narrated his life story with rehabilitation psychology providing mental health support during the initial stages of this project.

In the first step of this project, he compiled pictures and videos from his life experiences. The treatment team anticipated an emotional reaction as he began to sort through his pictures. In response to viewing a video recording of an early speech therapy session where he was asked to identify several common household objects, he was speechless and moved to tears as he realized the significance of his injuries early on. In the video, he was unable to identify the items. He had little recall of those early months in the hospital. Though he was told how far he had progressed, this moment was one of recognition of the extreme severity of his injury. In retrospect, this was the turning point that redefined and broadened his motivations and purpose for producing this movie. At this moment, he saw the potential of this project to be a source of motivation to others. As the breadth and scope of the project broadened, conversations in therapy sessions changed into a broader discussion of how this movie would impact those who see it. This shift in the focus of the project provided further opportunities to strengthen his communication skills and cognitive ability in the areas of planning and problem-solving.

In a recent conversation, he related that the original idea for finding a way to tell his story occurred to him less than a year after his injuries. He reflected that he had no way to express this idea because of the significant communication impairments until much later, and this project provided a means to set this idea in motion.

The overall plan for this movie continually evolved and he progressively set new goals to enhance the scope of the project. He started with a group of 25 pictures, which grew to 92 pictures, four video segments and two still-frame voice-over segments. Time was spent talking about each picture's significance and 
why he wanted to include each. Time was also spent organizing these pictures in chronological order, and the story began to take shape.

The first author, a Recreation Therapist (RT), taught him to use a laptop computer and movie editing software, providing an opportunity to develop his computer interface skills. He directed the formatting and assembly of the pictures into the software and the details of frame-to-frame transitions. He benefited from the development of to-do lists to keep in view all of the details that required his attention. A 3-ring binder proved to be a practical therapeutic tool to manage the development and sequence of the project as it evolved. The ability to physically manipulate the pages and to write notes on those pages facilitated forward progress from session to session. With the help of RT, he worked to make contacts with both the VAHCS community (team members who had provided care and rehabilitation therapy over the years), his family, friends and fellow military members of his home community. With these contacts, he began to plan all that was required for the premiere of his movie. Some of the tasks included: securing a site in the community to premiere his movie, working within VAHCS policy to allow a showing in the hospital, preparing to announce his movie with custom-designed invitations, and using other electronic forms to announce the premiere.

The second author, a Speech Language Pathologist (SLP), addressed rehabilitation of communication deficits throughout this project. This included helping him to communicate thoughts and ideas, practice writing skills, add detail to the descriptions of pictures, formulate his narrations into complete sentences, expand vocabulary and improve pronunciation skills.

He was highly motivated to tell his story as clearly as possible and to portray the significant impact of his life experiences. The best way to accomplish this, in his estimation, was to narrate the movie himself. This is an example of the lofty goals he sets for himself. After this goal was identified and set, he spent countless hours practicing pronunciation, adjusting length of narrations, and improving melody and inflection of his voice, and ultimately narrated all of the pictures in his own voice. Additionally, at the premiere, he orally presented his opening remarks to a live audience using only cue cards. All involved recognized the monumental significance of this accomplishment in the recovery of his communication abilities.

The end of the movie was always clear: he would show how he truly never quit by sharing his newest short-term goals and his long-term life goals. Despite an interesting life story portrayed by the pictures, the depth and strength of the emotion he was experiencing in clinic sessions was not coming across in the movie. It was informative and interesting, but did not capture his personality, energy and tenacity. One afternoon in a clinic session he brought in five additional pictures to include. These pictures showed him in his fatigues, wrestling in the middle of the desert. Through the conversation in this session, he expressed that he was participating in a wrestling tournament with hundreds of other military personnel. These pictures highlighted a tournament match that would advance the winner to the next level of competition. The first of the pictures portrayed him, fearless, marching toward a much larger opponent. The next picture showed the two men locked in a wrestling battle. The following two pictures showed him, pinned to the sand, apparently defeated. However, the final picture showed a superior officer declaring him the winner of the match. This wrestling match was a powerful metaphor for his life. It took time and much discussion, but he was able to draw the following parallels between the wrestling match and his life: he started strong (state champion wrestler, top of his class as a military recruit); was pinned to the sand by a seemingly undefeatable opponent (severely wounded by an RPG); almost losing the match (unlikely chances of surviving his injuries); ultimately winning the match (recovery and return to his home community). He persevered and succeeded in the wrestling match, and so he shall in his life.

In 2012, two significant events took place. The documentary film received two premiere showings at the VAHCS hospital. The premiere of his movie at the medical center coincided with the exact date of his injury, eight years earlier. As a result of the lengthy course of his rehabilitation, the achievement of many goals, and his winning attitude, he had become well known within the local VAHCS. His popularity resulted in "standing room only" in the medical center auditorium, at each showing. The second premiere event was held several days later at a Veterans of Foreign Wars (VFW) club, in his home community. He distributed invitations to his extensive network of friends and family. Once again there was an impressive turnout for both showings at the VFW. He wore his dress uniform to mark the significance of the occasions and proudly introduced his movie at each of the showings. He was well-rehearsed, and was able to calmly and confidently ad-lib during his opening remarks. The premiere events were met with praise and accolades from all who attended. He proudly received feedback and took time after each showing to interact with those who wished to congratulate him. 


\section{Discussion}

The main goals of this paper are (1) to present a case study of a U.S. military veteran who suffered a severe, penetrating/open head injury, completed rehabilitation and accomplished return to work in his home community, (2) to discuss factors that contribute to the outcome of this case, and (3) to describe the making of an autobiographical film as a relevant, functional final rehabilitation project. This case demonstrates the successful rehabilitation and part-time return to work, of one of the approximately 4,300 [1] U.S. military service members who were severely injured with a penetrating/open head injury over the past decade. Significant to the positive outcome of this case are a number of factors that warrant discussion here. The veteran presented in this case possesses characteristics, which the authors believe, prepared him to be successful in his recovery and rehabilitation. Before joining the military to serve his country, he was highly motivated, achievement-oriented and successful. He was a state champion high school wrestler. He achieved top honors in his military boot camp class and was a top contender as a wrestler in the U.S. Marines. During his short career in the military, he earned a distinguishing medal for bravery on the battlefield, "V for Valor", for saving the life of a fellow injured Marine. Just two weeks later, he suffered his own life-threatening injury. At this instant, the anticipated plans for his life took a dramatic turn. However, as a reflection of his true selfmotivation, he continued to live by the motto "Never Quit". He also articulated other life goals beyond the military. During a goal planning therapy session, he informed the rehabilitation team that his life-long goal was to become a professional movie director. At the time, in the face of significant communication, cognitive and physical challenges, this seemed like an audacious goal. In retrospect, it represents the kind of motivation and determination that made him successful throughout his life. He also expressed a desire to find a job locally so that he could have the opportunity to earn an income and contribute to his community.

The success of his rehabilitation was greatly benefitted by the ability of the rehabilitation specialists to work as an interdisciplinary team rather than from a more traditional multidisciplinary approach. In an article written by Redman 2006 [6], the author describes the interdisciplinary team approach as follows: "... two or more disciplinary perspectives collaborating in a manner so that the sum of the effort is greater than how each discipline might interpret a situation or what each discipline might produce individually." Working as an interdisciplinary team, the individual team members collaborated on specific, client-centered goals, each from the perspective of their own professional training and experience. This provided an individualized and tailored experience to the client. It required a high level of communication among team members, discussions about how the client-centered goals would be addressed, and often involved cotreatment sessions with more than one rehabilitation specialist.

The treatment team used a self-coaching therapy model which was based on collaborative goal setting [7], and his active participation in determining tasks and evaluating success. This resulted in the creation of a strong, therapeutic relationship, which in turn created a safe space for his creativity. The making of his movie was challenging. He was not always in agreement with suggestions made by the treatment team and often was frustrated by his communication difficulties. Some sessions were filled with tears of emotion and frustrating miscommunications. As the date of the premiere event approached, he became more anxious and emotional. Despite this, his true spirit prevailed, as most of the sessions were filled with humor, energy and forward progress.

He made significant gains toward the functional application of skills learned through years of therapy during his work on this movie project. Many skills applied during the production of his movie are now utilized in everyday life, at home and at work, and will be used for a lifetime. These include: understanding and communicating abstract thoughts; flexible thinking; problem-solving; decision-making; and contextual, non-self-centered choices. He improved his ability to communicate specific and complex ideas, both verbally and non-verbally. He has learned to better tolerate frustration. Acknowledgement of emotions, both his and that of others, has been a major benefit from his participation.

Shortly after the premiere showings of his movie, he began the initial search for a job in his home community. A local business owner and fellow community member, who attended a premiere showing of his movie at the VFW club, recognized his strength of character and determination portrayed in the movie. $\mathrm{He}$ also recognized his potential as a valuable employee in his retail store. An interview was arranged; a parttime position was offered and accepted. With the help of a job coach, he mastered the requirements of the job quickly. His job involves responsibility for the re- 
frigerated foods section of the store. He surveys the food items in the refrigerated section, then restocks needed items, organizes and cleans the walk-in refrigerator, and disposes of packing refuse from the stock items. In addition, he rotates the stock, checks the refrigerated food items for expiration dates, removes expired items from the stock, and disposes of the items according to store policy. When he started working at the store, the refrigerated stock was disorganized and stacked on the floor. He has significantly improved the organization and storage of stock items. Initially, adaptive tools were provided to him for manipulation and moving stock items. Through self-problem solving, he has been able to determine alternative ways to do his work duties more efficiently. At the time of this writing, he had successfully maintained this job for over 14 months.

He established and maintained a clear vision of his goals for this project. He knew what he needed to be able to communicate to accomplish his goals. He demonstrated the ability to stay the course, to complete his mission his way, and to never quit. These abilities enable him to continue his recovery, to meet his life goals, and to inspire others along the way.

\section{Summary}

Successful rehabilitation of severe traumatic brain injury, in this case, was accomplished due to a number of key factors. 1) He was determined, highly motivated and success-oriented with a clear view of his own goals, before and after his injury. He had achieved success prior to his injury and approached his rehabilitation and recovery with the same determination. 2)
The interdisciplinary rehabilitation team worked collaboratively with frequent communication, a common focus on client-centered goals and the willingness and flexibility to allow the client to "drive" his own rehabilitation goals and achievements. 3) He participated in collaborative goal setting during this project. He had significant input into rehabilitation goals he wanted to address, that were in alignment with his own future life goals. He had an inner motivation to achieve these goals and therefore realized great success. Completing the movie project, provided him with a perspective that he had recovered the skills necessary to seek and maintain gainful employment, in the face of significant, lingering effects of TBI. It also provided opportunities to practice and utilize the skills he had worked to recover, in an intrinsically motivating, practical project that was in stride with his future aspirations.

\section{References}

[1] Defense and Veterans Brain Injury Center website; (2013) Department of Defense (DoD) Worldwide Numbers for TBI; www.dvbic.org.

[2] Shank, John; Coyle, Catherine. Therapeutic Recreation in Health Promotion and Rehabilitation. State College, PA: Venture Pub., 2002. Print.

[3] Darley, Frederic L; Aronson, Arnold E; Brown, Joe R (1975). Motor Speech Disorders. Philadelphia, PA. W.B. Saunders Co.

[4] Sohlberg, M.M; Mateer, C.A. (2001). Cognitive Rehabilitation: An Integrative Neuropsychological Approach. New York, NY. The Guilford Press.

[5] Grohl, D. (2011). Walk [Recorded by Foo Fighters]. On Wasting Light [album]. Los Angeles, CA.

[6] Redman, R.W. (2006). Practice Environments: The Challenge of Interdisciplinary Teams. Research and Theory for Nursing Practice: An International Journal, 20(2), 105-107.

[7] McClain, C. (2005). Collaborative Rehabilitation Goal Setting. Topics in Stroke Rehabilitation, 12(4): 56-60. 